\title{
Biyogübre uygulamasının Cupressus arizonica ve Acer saccharum L. fidanlarının bazı morfolojik özelliklerine etkisi
}

\author{
Salih PARLAK (Orcid: 0000-0003-3808-3297)"1, Mustafa YILMAZ (Orcid: 0000-0002-8250-1882), \\ Orkun ÖZGÜN (Orcid: 0000-0001-7662-6219) ${ }^{\mathbf{1}}$, \\ ${ }^{1}$ Bursa Teknik Üniversitesi, Orman Fakültesi, Orman Mühendisliği Bölümü, BURSA \\ *Sorumlu yazar/Corresponding author: salih.parlak@btu.edu.tr, Geliş Tarihi/Recived: 21.02.2018, Kabul Tarihi /Accepted: 04.07.2018
}

$\ddot{\mathbf{O z}}$

Son yıllarda mineral gübreler yanında, besinlerin alımını sağlayan farklı bakteri türlerinin saf veya karışımlarını ihtiva eden biyogübreler kullanılmaya başlanmıştır. Tarımda yaygın olarak kullanılmasına rağmen biyogübrelerin orman fidanlıklarında kullanımı göreceli olarak yeni bir uygulamadır ve orman fidanlarının morfolojik karakterlerine etkileri konusunda yapılmış çalışmalar sınırlıdır. Bu çalışma, biyogübrelerin dış ortam şartlarında fidan yastıklarına uygulandığında fidan morfolojik karakterlerine etkilerinin belirlenmesi için gerçekleştirilmiştir. Çalışmada Bursa Orman Fidanlığında yastıkta yetiştirilen 1+0 yaşlı mavi servi (Cupressus arizonica) ve şeker akçaağacı (Acer saccharum) fidanları kullanılmıştır. Çok sayıda ticari biyogübre içinden, bileşimleri farklı bakterileri ihtiva eden iki farklı biyogübre çeşidi (Best-doll ve Bio-doll) seçilerek dört farklı doz (3 ml/1, 15ml/1, $30 \mathrm{ml} / 1$ ve kontrol) uygulaması yapılmış, bazı fidan morfolojik karakterlerine etkileri araştırılmıştır. C. arizonica ve $A$. saccharum fidanlarına uygulanan değişik biyogübreler ve dozları fidan boyu, kök boğaz çapı gibi bazı fidan morfolojik karakterlerinde anlamlı (belirgin) fark oluşturmuştur. A. saccharum fidanlarında Best-doll ve Bio-doll biyogübrelerinin $3 \mathrm{ml} / 1 \mathrm{doz}-$ ları kontrole göre fidan boyunu sırasıyla \% 13 ve \% 11, kök boğaz çapını ise sırasıyla \% 13 ve \% 16 artırmıştır. $C$. arizonica'nın ise kontrol grubu fidanları, her iki biyogübre uygulaması yapılan fidanlardan daha yüksek boy ve çap artımı sağlamıştır. Çalışmalara; birden fazla doz uygulama, farklı tür ve toprak şartlarında kullanım ve kimyasal gübrelerle kombine uygulamalar gibi konularda devam edilmelidir.

Anahtar Kelimeler: Biyogübre, Cupressus arizonica, Acer saccharum, morfolojik özellikler

\section{Effect of biogranulation on some morphological characteristics of Cupressus arizonica and Acer saccharum L. seedlings}

\begin{abstract}
In recent years, in addition to mineral fertilizers, biofertilizers containing the pure or mixture of different bacteria species that allow the uptake of nutrients have been used. Although widely used in agriculture, using of biofertilizers in forest nurseries is a relatively new application. There are limited researches about the effects of biofertilizers on morphological characteristics of forest tree seedlings, especially in outdoor environmental conditions of the nurseries. The current study was carried out to determine the effects of biofertilizers on the seedling morphological characteristics when applied on the seedbed of the forest nursery in outdoor conditions. In this research, $1+0$ old Arizona cypress (Cupressus arizonica) and sugar maple (Acer saccharum) seedlings were used in Bursa Forest Nursery. Among the numerous commercial biofertilizers, two biofertilizers containing different bacterial compositions were chosen and applied in four different doses $(3 \mathrm{ml} / 1,15 \mathrm{ml} / 1,30 \mathrm{ml} / 1$ and control) for each to determine the effects on some morphological seedling characteristics. The applied biofertilizers and doses on the seedlings of $C$. arizonica and A. saccharum significantly affected some morphological characteristics, such as the seedlings' heights and root collar diameters. In A. saccharum seedlings, $3 \mathrm{ml} / 1$ doses of both Best-doll and Bio-doll fertilizers increased the length of the seedlings by $13 \%$ and $11 \%$ and provided $13 \%$ and $16 \%$ better growth in the root collar diameters respectively, compared to the control. The $C$. arizonica control group seedlings produced higher diameters and height growths compared to two other biofertilized seedlings. The studies of biofertilizers should be continued on using of different doses, different forest tree species, soil conditions and the combined applications with chemical fertilizers.
\end{abstract}

Keywords: Bio-fertilizer, Cupressus arizonica, Acer saccharum, morphological characteristics

To cite this article (Atıf): PARLAK, S, YILMAZ, M , ÖZGÜN, O . (2018). Biyogübre uygulamasının Cupressus arizonica ve Acer saccharum L. fidanlarının bazı morfolojik özelliklerine etkisi. Ormancılık Araştırma Dergisi, 5 (2), 117-122.

DOI: https://doi.org/10.17568/ogmoad.397217

\section{Giriş}

Ağaçlandırma çalışmalarında başarının artırılmas1, bakım ve tamamlama giderlerinin düşürülmesi kullanılan fidanların kalitesine bağlıdır. Özellikle kurak ve yarı kurak alan ağaçlandırmalarında kullanılacak fidanların kök/sak oranının dengeli 
olması istenmektedir. Yetersiz veya aşırı beslenme fidanların kalitesinde bozulmalara yol açabilmektedir. Ekstrem ekolojik koşullarda yapılan ağaçlandırmalarda kullanılan fidanların, çok daha kaliteli ve kök/sak dengesinin kök lehine olması arzu edilmektedir. Bu dengenin kurulması, fidanlıktaki kültürel işlemlere bağlı olduğu kadar, toprağın besleme kapasitesi ve yarayışlı besin maddelerinin alınabilirliğine bağlıdır. Besin yetersizliği durumunda kimyasal gübrelerle takviye yapılmaktadır. Kimyasal gübrelerin yarayışı forma dönüştürülmeleri ve kolay alınabilmelerinde toprak mikroorganizmaları görev almaktadır. $\mathrm{Bu}$ bakımdan topraktaki mikroorganizma faaliyetinin fazlalığ verimliliğinin bir göstergesidir. Topraktaki besinlerden daha iyi faydalanabilmek için son yıllarda çeşitli bakteri türlerini ihtiva eden biyogübre uygulamaları yapılmaktadır. Bu gübreler tarım, orman ve süs bitkilerinde (Reddy, 2014) uygulama alanı bulmaktadır. Tarımsal ürünlerde verim artışı, hastalıklara karşı direnç, besin maddelerinden daha iyi faydalanma gibi hususlarda başarılı sonuçlar alınmıştır.

Biyogübreler; (biyolojik gübreler, bio-fertilizer, bakteriyel gübreler, bio-inokulantlar, bakteriyel inokulantlar, mikrobiyal kültürler) bitki için gerekli olan bitki besin maddelerinin sağlanmasında ve biyolojik yolla yarayışlı hale gelmesinde rol oynayan canlı mikroorganizmaların ticari formülasyonlarını ifade etmekte (Anonim, 2010) ve toprağa doğrudan ya da dolaylı olarak uygulanan mikroplar olarak bilinmektedir (Owen ve ark., 2015). Böylece topraktaki besin maddeleri daha etkin olarak kullanılmakta ve fidan kalitesi artmaktadır. Biyogübreler saçak kök oluşumunu teşvik etmesi nedeniyle (Benitez ve ark., 2004; Contreras-Cornejo ve ark., 2009) fidan tutma ve yaşama oranlarını artırmaktadır. Toprak kaynaklı zararlı patojenleri baskılarken, faydalı bakterileri etkinleştirdiğinden bitkilerin biyokütlesini önemli derecede artırdığı ispatlanmıştır (Siddiqui, 2006). Azot ve fosfor al1mını sağlayarak (Hasrat, 2006) kök sistemlerinin gelişimini ve ürün miktarını (Owen ve ark., 2015) artırmaktadir.

Biyogübreler faydalarına ve fonksiyonlarına göre; azot bağlayanlar, fosfatı çözenler, potasyumu çözenler, sülfürü okside edenler, silikatı çözenler, dekompoze kültürler olarak ayrılabilir. Azot bakterileri ise kendi arasında simbiyotik ve simbiyotik olmayan azot bakterileri şeklinde ayrilır. Rhizobium, Azolla gibi simbiyotik, Azotobacter, Acetobacter, Beijerinekia, Azospirillum gibi simbiyotik olmayan bakteriler havanın serbest azotunu bağlarlar. Pseudomonas, Bacillus, Aspergillus ve
Penicillium bakterileri ise fosforun serbest hale geçmesinde etkilidirler (Borkar, 2015). Mikroorganizmaların, kimyasal gübreler ve pestisitlerin oluşturduğu problemleri çözmede alternatif olmaları nedeni ile organik tarımda kullanılmaları oldukça yaygınlaşmıştır (Berg, 2009).

Oysa ormancılıkta kullanımı konusunda yapılan çalışmalar sınırlıdır. Bunlardan en fazla bilineni Rhizobium bakterileri olup, baklagillerin köklerinde simbiyotik yaşayarak azot bağlarlar. Aktinomisetler ise orman ağaçlarından kızılağaç, ılgın, iğde gibi ağaçların köklerinde küçük yumrular meydana getirerek azot bağlarlar (Anonim, 2010). Orman fidanlarına biyogübre uygulaması ve fidan morfolojik karakterlerine etkileri konusunda yapılmış çalışmalar olmasına rağmen, (Shishido ve Chanway, 2000; Karthıkeyan ve Suryaprakash, 2008; Kuppurajendran, 2012; Rajeshkumar ve ark., 2009; Bergottini ve ark., 2015; Sreedhar ve Mohan, 2016) bu çalışmaların birçoğu laboratuvar ortamında yapılmış saksı denemelerini içermektedir (Malusá ve ark., 2012).

$\mathrm{Bu}$ çalışma, dış ortam şartlarında fidan yastıklarında gerçekleştirilmiş, mavi servi (Cupressus arizonica) ve şeker akçaağacı (Acer saccharum) türlerinde iki farklı biyogübre (Best-doll ve Bio-doll) uygulamasının fidan morfolojik karakterlerine etkilerinin ortaya konulması amaçlanmıştır.

\section{Materyal ve Yöntem}

\section{1. Çalışma alanının tanıtımı ve fidanlık çalışmaları}

Çalışma 89m rakımda bulunan Bursa Orman Fidanlığında gerçekleştirilmiştir. Bursa'nın 19262016 yılları arasındaki iklim verileri; yıllık ortalama sicaklık $14,6^{\circ} \mathrm{C}$; en sicak ay ortalaması temmuz $24,5^{\circ} \mathrm{C}$ ve en soğuk ay ortalaması ise $5,3^{\circ} \mathrm{C}$ ile ocak ayıdır. Yıllık yağış ortalaması 707,5 mm olup yaz ayları yağış toplamı $71,5 \mathrm{~mm}$ olarak hesaplanmıştir.

Ekim yastıkları $120 \mathrm{~cm}$ eninde olup C. arizonica tohumları beş, A. saccharum tohumları dört sıralı olarak 2016 yılı Nisan ayında ekilmiştir. Biyogübre uygulamas1 yapılan parsellerde $\mathrm{m}^{2}$ de $C$. arizonica'da 46 ve $A$. saccharum'da 50 fidan bulunacak şekilde seyreltme uygulaması yapılmıştır. Biyogübre uygulaması yapılmadan önce verilen gübrelerin birbirini etkilememesi için fidan yastıklarında parsel aralarına toprağın $30 \mathrm{~cm}$ derinliğine kadar plastik plakalar konulmuştur. Vejetasyon dönemi boyunca yastıklarda rutin ot alma, sulama ve kök kesimi faaliyetleri gerçekleştirilmiştir. 
Biyogübrelerin firma tarafından içeriği garanti edilen toplam mikroorganizma sayıs $2 \times 10^{7} \mathrm{kob} / \mathrm{ml}$ ve etkin olduğu pH aralığ 1 4-9 olarak belirtilmiştir (Tablo 1). Çalışmada her iki biyogübrenin $3 \mathrm{ml} / \mathrm{m}^{2}$, $15 \mathrm{ml} / \mathrm{m}^{2}, 30 \mathrm{ml} / \mathrm{m}^{2}$ ve kontrol dozları kullanılmış- tır. Her bir doz hazırlanan şekerli su solüsyonunda $(50 \mathrm{~g} / 1) 24$ saat bekletilerek bakterilerin çoğalmaları temin edilmiş, daha sonra hazırlanan dozajlar 10 litre saf suya karıştırılarak çoğaltılmıştır.

Tablo 1. Biyogübrelerin içeriği ve deneme deseni

Table 1. Contents of biofertilizers and study design

\begin{tabular}{|c|c|c|c|c|c|}
\hline Uygulama & İçerik & Tür & $\begin{array}{c}\text { Dozlar } \\
(\mathrm{ml} / \mathrm{l})\end{array}$ & Tekerrür & $\begin{array}{l}\text { Toplam uygulama alanı } \\
\qquad\left(\mathrm{m}^{2}\right)\end{array}$ \\
\hline \multirow{6}{*}{ Best-doll } & Penicilium bilaii & & & & \multirow{6}{*}{6} \\
\hline & Bacillus megaterium & A. saccharum & 3 & 3 & \\
\hline & Artrobacter viscosus & & & & \\
\hline & Azotobacter vinelandii & & 15 & & \\
\hline & Azotobacter chroococcum & C. arizonica & & 3 & \\
\hline & Pseudomanas sp. & & 30 & & \\
\hline \multirow{2}{*}{$\begin{array}{l}\text { Kontrol } \\
\text { (Best-doll) }\end{array}$} & & A. saccharum & \multirow{2}{*}{0} & 3 & \multirow{2}{*}{6} \\
\hline & & C. arizonica & & 3 & \\
\hline \multirow{4}{*}{ Bio-doll } & Bacillus polymyxa & & & & \multirow{4}{*}{6} \\
\hline & Azospirillium brasilence & A. saccharum & 3 & 3 & \\
\hline & Arthrobacter paraffineus & C. arizonica & 15 & & \\
\hline & Pseudomanas sp. & & 30 & 3 & \\
\hline \multirow{2}{*}{$\begin{array}{l}\text { Kontrol } \\
\text { (Bio-doll) }\end{array}$} & & A. saccharum & \multirow{2}{*}{0} & 3 & \multirow{2}{*}{6} \\
\hline & & C. arizonica & & 3 & \\
\hline
\end{tabular}

Çalışma, Rastlantı parselleri deneme desenine"ne uygun kurulmuştur. Süzgeçli sulama kovasıyla 1 $\mathrm{m}^{2}$ 'lik fidan yastıklarına her doz üç yinelemeli olarak 28.06.2016 tarihinde tek uygulama olarak yapılmıştır. Ayrıca tesadüfî olarak belirlenen ve biyogübre uygulanmayan altı kontrol parseli alınmıştır. Biyogübrenin fidan karakteristikleri üzerindeki etkisinin ortaya konabilmesi için vejetasyon dönemi sonunda tüm fidanların boyları ve kök boğaz çapları ölçülmüştür. Fidanlar 20.07.2016 tarihinde rutin bir uygulama olan kök kesimine tabi tutulmuş, 26.11.2016 tarihinde yapılan ikinci kök kesimini takiben yastıktan elle sökülmüştür.

\subsection{Verilerin değerlendirilmesi}

Biyogübrenin etkisinin belirlenebilmesi için fidanların vejetasyon dönemi sonunda ölçülen çap ve boy değerleri istatistiki analizlerde kullanılmıştır. Verilerin normallik denetimi yapılmış, normal dağılım göstermeyen fidan boyu (FB), kök boğaz çap1 (KBÇ) değerlerine logaritma dönüşümü uygulanmıştır. Farklı biyogübre ve dozlarının $A$. saccharum ve $C$. arizonica fidanlarının morfolojik özelliklerine etkisi belirlenmesinde tek yönlü varyans analizi (ONEWAY-ANOVA) kullanılmış, sonuçlar Duncan çoklu karşılaştırma testi ile denetlenmiştir. İstatistik analizlerde SPSS 22.0 paket programı kullanılmıştır (SPSS v.22.0®, 2015). Araştırmada $y_{i j}=\mu+\alpha_{i}+\varepsilon_{i j}$ istatistik modeli kullanılmıştır. Modelde $y_{i j}$ : farklı biyogübre uygulamasına tabi tutulmuş bir fidana ait morfolojik özelliği, $\mu$ : bir fidan özelliğine ait genel ortalama değeri, $\alpha_{i}$ : biyogübrenin etkisini, $\varepsilon_{i j}$ : raslantı hatasinı ifade etmektedir.

\section{Bulgular}

\subsection{Uygulanan biyogübrelerin Acer saccharum fidanlarının morfolojik karakterlerine etkisi}

Yapılan varyans analizi sonucunda; biyogübre çeşitlerinin fidan boylarında etkili fakat kök boğaz çapı bakımından etkisiz olduğu belirlenmiştir. Dozlar ise boy ve kök boğaz çapında istatistiki olarak anlamlı fark oluşturmuştur (Tablo 2). Her iki gübrede $3 \mathrm{ml} / \mathrm{m}^{2}$ doz uygulanan $A$. saccharum fidanları daha yüksek boy büyümesi ve kök boğaz çapı artışı sağlamıştır. (Tablo 3).

Uygulanan biyogübre dozlarının $A$. saccharum fidanlarının boy ve kök boğaz çapına etkisi Tablo 
Tablo 2. Gübre cins ve dozlarına göre $A$. saccharum fidanlarının varyans analizi

Table 2. Analysis of variance for $A$. saccharum seedlings by fertilizer types and doses

\begin{tabular}{lrrrr}
\hline $\begin{array}{l}\text { Varyasyon } \\
\text { kaynağ } 1\end{array}$ & \multicolumn{2}{c}{$\begin{array}{c}\text { Fidan Boyu } \\
(\mathrm{cm})\end{array}$} & \multicolumn{2}{c}{$\begin{array}{c}\text { Kök boğaz1 çap1 } \\
(\mathrm{mm})\end{array}$} \\
\cline { 2 - 5 } & F oran1 & Sig. & F oran1 & Sig. \\
\hline Gübre çeşidi & 8,219 & 0,04 & 1,584 & 0,209 \\
Gübre dozu & 30,320 & 0,000 & 36,991 & 0,000 \\
\hline
\end{tabular}

Tablo 3. A. saccharum fidanlarının doza bağlı boy ve çap gelişimlerine ait Duncan testi sonuçları

Table 3. Duncan test for height growth and diameter increment of $A$. saccharum seedlings

\begin{tabular}{cccc}
\hline $\begin{array}{c}\text { Gübre dozu } \\
(\mathrm{ml} / \mathrm{l})\end{array}$ & Adet & $\begin{array}{c}\text { Fidan boyu } \\
(\mathrm{cm}) \\
(\text { Ort. } \pm \mathrm{SS})\end{array}$ & $\begin{array}{c}\text { Kök boğaz1 } \\
\text { çap1 } \\
(\mathrm{mm}) \\
(\mathrm{Ort} . \pm \mathrm{SS})\end{array}$ \\
\hline Kontrol & 136 & $93,6 \pm 19,5 \mathbf{b}$ & $9,82 \pm 2,39 \mathbf{b}$ \\
3 & 151 & $105,7 \pm 21,6 \mathbf{a}$ & $11,47 \pm 2.96 \mathbf{a}$ \\
15 & 151 & $86,1 \pm 15,0 \mathbf{c}$ & $8,63 \pm 1,91 \mathbf{c}$ \\
30 & 175 & $93,6 \pm 16,0 \mathbf{b}$ & $9,88 \pm 2.07 \mathbf{b}$ \\
\hline
\end{tabular}

4'te verilmiştir. Kontrole göre, Best-doll biyogübrenin $3 \mathrm{ml} / 1$ dozu \% 13 ve Bio-doll biyogübrenin 3 $\mathrm{ml} / 1$ dozu \% 11 boy artışı sağlamıştır. Kök boğaz çapında ise Best-doll biyogübre çeşidi \%13, Biodoll biyogübre çeşidi ise \% 16 artım meydana getirmiştir (Tablo 4).

Tablo 4. Uygulanan biyogübre dozlarının $A$. saccharum fidanlarının boy ve kök boğaz çapına etkisi

Table 4. The effects of applied biofertilizer doses on

height and root collar diameters of $A$. saccharum seedlings

\begin{tabular}{lcccc}
\hline $\begin{array}{l}\text { Biyogübre } \\
\text { çeşidi }\end{array}$ & $\begin{array}{c}\text { Biyogübre } \\
\text { dozu } \\
(\mathrm{ml} / \mathrm{l})\end{array}$ & $\begin{array}{c}\text { Fidan } \\
\text { adedi }\end{array}$ & $\begin{array}{c}\text { Fidan } \\
\text { boyu } \\
(\mathrm{cm})\end{array}$ & $\begin{array}{c}\text { Kök } \\
\text { boğaz1 } \\
\text { çap1 } \\
(\mathrm{mm})\end{array}$ \\
\hline \multirow{3}{*}{ Best-doll } & 3 & 67 & 107,6 & 11,26 \\
& 15 & 85 & 82,0 & 8,52 \\
& 30 & 101 & 90,5 & 9,97 \\
\hline \multirow{3}{*}{ Bio-doll } & 3 & 84 & 104,1 & 11,62 \\
& 15 & 66 & 91,3 & 8,76 \\
& 30 & 74 & 97,7 & 9,74 \\
\hline
\end{tabular}

\subsection{Biyogübrelerin Cupressus arizonica} fidanlarının morfolojik karakterlerine etkileri

Yapılan varyans analizi sonucunda; uygulanan biyogübre cinsleri arasında fidan boyları ve çapları bakımından fark oluşmazken, uygulanan dozla- rın boy ve kök boğaz çaplarında istatistiki olarak anlamlı fark oluşturduğu belirlenmiştir (Tablo 5). Yapılan Duncan testinde her iki gübrede de kontrol parselindeki $C$. arizonica fidanları daha iyi boy büyümesi ve kök boğaz çapı gelişimi sağlamıştır (Tablo 6).

Tablo 5. Gübre cins ve dozlarına göre $C$. arizonica fidanlarının varyans analizi

Tablo 5. Analysis of variance for C. arizonica seedlings by fertilizer types and doses"

\begin{tabular}{lcccc}
\hline $\begin{array}{l}\text { Varyasyon } \\
\text { kaynağ1 }\end{array}$ & \multicolumn{2}{c}{$\begin{array}{c}\text { Fidan boyu } \\
(\mathrm{cm})\end{array}$} & \multicolumn{2}{c}{$\begin{array}{c}\text { Kök boğazı çap1 } \\
(\mathrm{mm})\end{array}$} \\
\cline { 2 - 5 } & F oran1 & Sig. & F oran1 & Sig. \\
\hline Güre çeşidi & 1.060 & 0,304 & 0,360 & 0,549 \\
Gübre dozu & 5,008 & 0,002 & 3,137 & 0,025 \\
\hline
\end{tabular}

Tablo 6. C. arizonica fidanlarının doza bağlı boy ve çap gelișimlerine ait Duncan testi sonuçları

Table 6. Duncan test for height growth and diameter increment of $C$. arizonica seedlings

\begin{tabular}{lccl}
\hline $\begin{array}{l}\text { Gübre dozu } \\
(\mathrm{ml} / \mathrm{l})\end{array}$ & Adet & $\begin{array}{c}\text { Fidan boyu } \\
(\mathrm{cm})\end{array}$ & $\begin{array}{c}\text { Kök boğaz1 çap1 } \\
(\mathrm{mm})\end{array}$ \\
\hline Kontrol & 128 & $55,6 \pm 14,1 \mathbf{a}$ & $7,73 \pm 2.01 \mathbf{a}$ \\
3 & 144 & $51,5 \pm 11,8 \mathbf{b}$ & $7,58 \pm 1,93 \mathbf{a b}$ \\
15 & 135 & $50,2 \pm 10,8 \mathbf{b}$ & $7,10 \pm 1,82 \mathbf{b}$ \\
30 & 145 & $51,4 \pm 11,1 \mathbf{b}$ & $7,22 \pm 1,94 \mathbf{b}$ \\
\hline
\end{tabular}

Uygulanan biyogübre dozlarının $C$. arizonica fidanlarının boy ve kök boğaz çapına etkisi Tablo 7 'de verilmiştir. Her iki biyogübre çeşidinin kontrol dozu diğerlerinden daha fazla boy artımı sağlamıştır. Kök boğaz çapını ise $30 \mathrm{ml} / 1$ Best-doll biyogübre çeşidi sadece \% 1 artırmış, Bio-doll biyogübre çeşidi ise etkisiz bulunmuştur (Tablo 7).

Tablo 7. Uygulanan biyogübre dozlarının C. arizonica fidanlarının boy ve kök boğaz çapına etkisi

Table 7.The effects of applied biofertilizer doses on height and root collar diameters of $C$. arizonica seedlings

\begin{tabular}{lcccc}
\hline $\begin{array}{l}\text { Biyogübre } \\
\text { çeşidi }\end{array}$ & $\begin{array}{c}\text { Biyogübre } \\
\text { dozu } \\
(\mathrm{ml} / \mathrm{l})\end{array}$ & $\begin{array}{c}\text { Fidan } \\
\text { adedi }\end{array}$ & $\begin{array}{c}\text { Fidan } \\
\text { boyu } \\
\text { (cm) }\end{array}$ & $\begin{array}{c}\text { Kök boğaz1 } \\
\text { çap1 } \\
(\mathrm{mm})\end{array}$ \\
\hline Kontrol & 64 & 55,4 & 7,69 \\
& 3 & 64 & 53,4 & 7,64 \\
& 15 & 76 & 48,0 & 6,81 \\
Bio-doll & 30 & 65 & 54,6 & 7,76 \\
\hline & 3 & 80 & 49,9 & 7,51 \\
& 15 & 59 & 53,1 & 7,47 \\
\hline
\end{tabular}




\section{Tartışma ve Sonuç}

Yaptığımız çalışmada fidanların boy ve kök boğaz çapı gelişimi bakımından biyogübre çeşitlerinin sadece Acer saccharum fidanlarının boy gelişiminde etkili, Cupressus arizonica fidanlarında etkili olmadığı belirlenmiştir. Biyogübre dozlarının ise hem A. saccharum hem de C. arizonica fidanlarının boy ve çap gelişiminde anlamlı fark oluşturduğu belirlenmiștir. Best-doll ve Bio-doll gübrelerinin $3 \mathrm{ml} / 1$ dozu $A$. saccharum fidanlar1nın boy gelişimini kontrole göre sırasıyla $\% 13$ ve \% 11; kök boğaz çapını ise \% 13 ve \% 16 artırmıştır. Best-doll biyogübre çeșidi $A$. saccharum boy ve çap artımında dalgalı bir seyir izlemiş, $15 \mathrm{ml}$ dozdaki artış diğer dozlardan düşük kalmıştır. Biodoll biyogübre çeşidinin kontrole göre daha fazla boy artışı sağlaması, bileşiminde Azospirillum grubu bakterilerin varlığına bağlı olabilir. Çünkü Azospirillum bakterilerinin Azotobacter ile kiyaslandığında yaklaşık üç kat daha fazla azot bağladığ1 bildirilmektedir (Borkar, 2015).

Kuppurajendran (2012), Erythrina indica sürgün uzunluğu bakımından Azospirillum ile bulaşık fidanların kontrole göre boyda $\% 57,71$ ve kök uzunluğunda \%41,76 artış sağladığını belirlemiştir. Azospirillum + AM fungi+ Pseudomonas kombinasyonu uygulanan Feronia elephantum (Corr.) fidelerinde kontrole göre kök uzunluğunun \% 56,81, sürgün boyunun $\% 22,72$ ve kök boğazı çapının ise \% 108,57 arttı $\breve{g}_{1}$ bildirilmektedir (Deshmukh ve ark., 2007). Rajeshkumar ve ark. (2009), Melia azedarach L.'taki çalışmalarında Glomus geosporum, Azotobacter chroococcum ve Bacillus coagulans uygulanan fidanların kök ve sürgün boylarını kontrole göre daha yüksek bulmuşlardır.

Bu çalışmada kullanılan diğer tür olan C. arizonica fidanlarına uygulanan biyogübre çeşitleri ise çap ve boy artımında etkisiz bulunmuştur. Fakat uygulanan dozlara bakıldığında, kontrol grubu fidanları boy ve çap gelişimi bakımından uygulanan tüm dozlardan daha yüksek değerler vermiştir.

Bio-doll terkibine benzer olarak, Azotobacter, Pseudomonas ve Bacillus bakterileri bulunan biyogübreler ile farklı sonuçlar elde eden çalışmalar mevcuttur. Asif ve ark. (2013), Azotobacter'in fidan boyunu kontrole göre \% 37,17 artırdığını belirlemişlerdir. Picea glauca (Moench) Voss $\times$ Picea engelmannii Parry ex Engelm.) hibritlerinin tohumlarına yapılan Pseudomonas ve Bacillus uygulaması \% 10-234 arasında sürgün ve kök artışı sağlamıştır (Shishido ve Chanway, 2000). Azotobacter uygulanan fidanların gelişimlerinin nispeten düşük kaldığına dair çalışmalar ile (Paroha ve ark., 2000) biyogübrelerin kök boğaz çapını artırdığına dair çalışmalar mevcuttur. Asif ve ark. (2013), fark1 biyogübreler ile yaptıkları çalışmada kök boğaz çapını \% 8,84 ile \% 16,87 arasında artırdığını belirlemişlerdir. Azospirillum uygulanan fidanlarda ise (Kuppurajendran, 2012) kök boğazı çapı kontrole göre \% 75,54 artış göstermiştir. Mohan ve Rajendran (2014), biyogübre bileşiminin kök, sak ve kök boğazı çapını ortalama \% 77,47 oranında artırdığını belirlemişlerdir. Parlak ve Güner (2017), iki yaşlı karaçam fidanlarına uygulanan biyogübrenin fidan karakterlerinde anlamlı bir fark meydana getirmediğini bildirmişlerdir. Bu konuda çalışan Alori ve ark. (2017) ise uygulanan bazı biyogübrelerin toprağın mikrobiyallerini artırma veya azaltma bakımından etkisiz olabildiğini ifade etmektedirler.

$\mathrm{Bu}$ çalışmada biyogübre uygulamasının fidan boyu ve kök boğazı çapı gibi bazı fidan morfolojik özelliklerinde kısmen etkili bulunmakla birlikte, literatürde belirtilen değerlere ulaşılamamıştır. Biyogübre ile ilgili çalışmalara farklı fidanlık, toprak tipi, ağaç türü, tohuma uygulama, uygulama sayısı ve dozu ile biyokütle miktarına etkisinin belirlenmesi gibi konularda devam edilmelidir.

Teşekkür: Bu çalışma (Proje Numarası: 2016-02007) Bursa Teknik Üniversitesi, Bilimsel Araştırma Projeleri Birimi tarafından desteklenmiştir.

\section{Kaynaklar}

Alori, E.T., Dare, M, O., Babalola, O.O., 2017. Microbial Inoculants for soil quality and plant health. Sustainable Agriculture Reviews 22: 281-307

Anonim, 2010. Tarımda Kullanılan Organik, Organomineral Gübreler ve Toprak Düzenleyiciler ile Mikrobiyal, Enzim İçerikli ve Diğer Ürünlerin Üretimi, İthalat1 ve Piyasaya Arzına dair Yönetmelik. 4 Haziran 2010 tarih ve 27601 sayılı Resmî Gazete

Asif, M., Lone, S., Lone, F.A., Hamid, A., 2013. Field performance of blue pine (Pinus wallichiana) seedlings inoculated with selected species of bio-inoculants under nursery conditions. International Journal of Pharma and Bio Sciences 4(1): (B) 632-640

Benitez, T., Rincon, A.M., Limon, M.C., Codon, A.C., 2004. Biocontrol mechanisms of Trichoderma strains. Int. Microbiology 7: 249-260

Berg, G., 2009. Plant-microbe interactions promoting plant growth and health: perspectives for controlled use of microorganisms in agriculture. Applied Microbiology and Biotechnology 84: 11-18 
Bergottini, V.M., Otegui, M.B., Sosa, D.A., Zapata, P.D., Mulot, M., Rebord, M., Zopfi, J., Wiss, F., Benrey, B., Junier, P., 2015. Bio-inoculation of yerba mate seedlings (Ilex paraguariensis St. Hill.) with native plant growth-promoting Rhizobacteria: a sustainable alternative to improve crop yield. Biology and Fertility of Soils 51(6): 749-755

Borkar, S.G., 2015. Microbes as Biofertilizers and Their Production Technology, Woodhead Publishing India Pvt. Ltd., 218p.

Contreras-Cornejo, H.A., Macías-Rodríguez, L., CortésPenagos, C., López-Bucio, J., 2009 Trichoderma virens a plant beneficial fungus, enhances biomass production and promotes lateral root growth through an auxin-dependent mechanism in Arabidopsis. Plant Physioogyl 49: 1579-1592

Deshmukh, A.M., Khobragade, R.M., Dixit, P.P., 2007. Handbook of Biofertilizers and Biopesticides. Oxford Book Company 267, 10-B-Scheme, Opp. Narayan Niwas, Gopalpura By Pass Road, Jaipur-302018, 326p.

Hasrat, A., 2006. Agro Technology of Organic Farming. Published by: Grassroots Institute c/o Grassroots India Trust 1st Floor, 134, Street 17, Zakir Nagar, Okhla, Opp. New Friends Colony A-Block, New Delhi - 110 025, 21p.

Karthikeyan, A., Suryaprakash, M., 2008. Effects of arbuscular mycorrhizal fungi, Phosphobacterlum and Azospirillum sp. on the successful establishment of $E u$ calyptus camaldulensis Dehn. in bauxite mine soils. Forests and Trees and Livelihoods 18 (2): 183-191

Kuppurajendran, 2012. Effects of bioinoculants on seedling growth, biochemical changes and nutrient uptake of Erythrina indica L. in semi arid region of Southern India. Biometrics \& Biostatistics 3:2, DOI: 10.4172/21556180.1000134

Malusá, E., Sas-Paszt, L., Ciesielska, J., 2012. Technologies for beneficial micro-organisms inocula used as biofertilizers. The Scientific World Journal [Online]. Available:http://www.ncbi.nlm.nih.gov/pmc/articles/ PMC3324119/ doi:10.1100/2012/491206 (Erişim tarihi: 09.09.17)

Mohan, E., Rajendran, K., 2014. Effect of plant growthpromoting microorganisms on quality seedling production of Feronia elephantum (Corr.) in semi-arid region of
S. India. International Journal of Current Microbiology and Applied Sciences 3(7): 103-116

Owen, D., Williams, A.P., Griffith, G.W., Withers, P.J.A., 2015. Use of commercial bio-inoculants to increase agricultural production through improved phosphorus acquisition. Applied Soil Ecology 86: 41-54

Parlak S., Güner, D., 2017. Mikrobiyal gübre uygulamasının karaçam (Pinus nigra Arnold. subsp. pallasiana (Lamb.) Holmboe) fidanlarının bazı morfolojik özelliklerine etkisi. Ormancılık Araștırma Dergisi, A, 4: 2, 100-106, DOI: http://dx.doi.org/10.17568/ogmoad. 337884

Paroha, S., Chandra, K.K., Tiwari, K.P., 2000. Synergistic role of VAM and Azotobacter 1noculation on growth and biomass production in forestry species. Journal of Tropical Forestry 16(1): 13-21

Rajeshkumar, S., Chandran Nisha, M., Chidambaram Prabu P., Wondimu, L., Selvara, T., 2009. Interaction between Glomus geosporum, Azotobacter chroococcum and Bacillus coagulans and their influence on growth and nutrition of Melia azedarach L. Turkısh Journal of Biology 33: 109-114

Reedy, P.P., 2014. Plant Growth Promoting Rhizobacteria for Horticultural Crop Protection. ISBN 978-81-3221973-6 (eBook), Springer. New Delhi, Heidelberg, New York, Dordrecht, London, 313p.

Shishido M., Chanway C.P., 2000. Colonization and growth promotion of out planted spruce seedlings preinoculated with plant growth promoting Rhizobacteria in the greenhouse. Canadian Journal of Forest Research 30(6): $845-854$

Siddiqi, Z. A. 2006. PGPR: Prospective biocontrol agents of plant pathogens. In PGPR: Biocontrol and biofertilization, 111-42. Dordrecht, The Netherlands: Springer

SPSS v.22.0, 2015. SPSS 22.0 Guide to Data Analysis, published by Prentice Hall, Upper Saddle River, New Jersey, USA. 637 pp.

Sreedhar, S.S., Mohan V., 2016. Effect of different plant growth promoting microbes as bio-inoculants on the growth improvement of Ailanthus excelsa seedlings in nursery. The Indian Foresters 142 (7): 631-641 